\title{
Entrevista con Mons. Pedro A. Aparicio Obispo de San Vicente (1949-1983)
}

\section{Julian Filochowski \\ Chair, The Archbishop Romero Trust Londres}

En 1979 estuve presente en la Tercera Conferencia General del Episcopado Latinoamericano, la cual tuvo lugar en Puebla (México). En ese entonces, trabajaba como periodista del británico The Catholic Herald. Durante la Conferencia, junto con otros dos periodistas, realicé y grabé esta entrevista con Mons. Pedro Arnoldo Aparicio, en la tarde del lunes 5 de febrero, en el Seminario Palafoxiano. En la sede de la Conferencia había una sala de prensa y algunos documentos de referencia a disposición de los periodistas. Pero no podíamos asistir a las reuniones plenarias, ni a los grupos de trabajo de la Conferencia. Tampoco teníamos acceso a los comentarios cotidianos de las personalidades que tomaban parte en los debates. Sin embargo, ese lunes, los periodistas pudimos reunirnos con algunos de los participantes en la Conferencia. Por razones y motivos diferentes, nosotros tres solicitamos una entrevista con Mons. Aparicio.

La entrevista empezó a las 3:30 p.m. y duró más de una hora. A veces, el hilo de la entrevista cambió de dirección, porque los entrevistadores éramos tres y porque nuestros intereses eran diferentes. Por eso, en la transcripción se observan algunas discontinuidades. Mientras nosotros cambiábamos la cinta, Mons. Aparicio continuaba hablando. En ese momento, él presidía la Conferencia Episcopal de El Salvador (Cedes). Y fue el único delegado elegido por la conferencia. Mons. Óscar A. Romero, arzobispo de San Salvador, también estuvo presente en Puebla, pero ex officio, dado que era miembro de la Pontificia Comisión para América Latina (CAL).

Cuando comenzó Puebla, Mons. Romero tenía dos años de ser arzobispo de San Salvador. Habían sido dos años de gran tensión, de conflicto social y de represión. Mons. Romero se había puesto a sí mismo y había puesto inequívo- 
camente a la arquidiócesis al lado de los pobres y de su lucha por los derechos humanos y la justicia económica. En esos dos años, habían sido asesinados cuatro sacerdotes: Rutilio Grande, el 12 de marzo de 1977; Alfonso Navarro, el 11 de mayo de 1977; Ernesto Barrera, el 28 de noviembre de 1978; y dos semanas antes de la entrevista, el 20 de enero de 1979, durante una operación militar, fueron asesinados Octavio Ortiz y cuatro jóvenes, que participaban en un retiro, en el centro El Despertar, donde aquel residía.

En una declaración a Associated Press (AP), tres días antes de la entrevista, Mons. Aparicio culpó a "ciertos jesuitas" del conflicto que agobiaba al país, responsabilizó a los teólogos de adoctrinar maliciosamente al clero y negó que Mons. Romero defendiera a las clases oprimidas. Agregó que este más bien ofendía gratuitamente al gobierno de El Salvador. Este es el trasfondo de la entrevista, la cual transcribí esa misma noche, en mi hotel, con la ayuda de Juan Hernández Pico, S. J., y de Jon Sobrino, S. J. Al día siguiente, entregué el texto a la presidencia de la Conferencia. Posteriormente, esta ordenó a Mons. Aparicio no hacer más declaraciones a los medios de comunicación durante su estadía en Puebla.

Al leer la entrevista, se comprende por qué esta no se publicó en aquel momento. Habría puesto en peligro no solo la vida de los jesuitas, sino también la de los demás sacerdotes y la de quienes dirigían los programas de la pastoral rural. Parece oportuno publicarla hoy, cuando la causa de canonización de Mons. Romero cobra fuerza, para mostrar el contexto eclesiástico adverso, en el cual el arzobispo realizó su ministerio evangelizador y profético.

\section{Entrevista de Mons. Pedro Arnoldo Aparicio con tres periodistas}

Puebla, 5 de febrero de 1979, hora: 3:30 p.m.

Periodista (P.). Ya puede empezar, Monseñor, ¿cuál ha sido su reacción frente a la muerte de dos sacerdotes, en las semanas recientes, en El Salvador?

Mons. Aparicio (M.A.). Mire, en cuanto a estos problemas, cada obispo, cada diócesis, es responsable de los problemas de su diócesis. Si él los lleva al seno de la conferencia episcopal, entonces la conferencia episcopal se pronuncia y estudia. Pero los dos últimos no han sido llevados al seno de la conferencia episcopal.

P. Pero, por ejemplo, en Chile, cuando hay un problema así, el presidente de la conferencia episcopal, por su propia posición...

M.A. Iniciativa...

P. Exactamente: iniciativa, habla cuando hay un atropello contra la Iglesia, como este.

M.A. Pero en El Salvador, desgraciadamente, no podemos decir esto. Hay un grupo de sacerdotes que, en realidad, están comprometidos con las izquierdas. 
P. ¿Y esto justifica que se maten?

M.A. No justifica que se maten, pero les han seguido los pasos. Yo tengo lástima que no sabía que me iban a preguntar sobre eso-, traigo cintas grabadas y documentación bastante fuerte. No permiten que se maten, ni estamos por esa violencia en esa forma, pero sabemos que los cuerpos de seguridad saben perfectamente bien los pasos que estos sacerdotes han llevado. El supremo gobierno, por lo menos, cuatro o cinco veces ha reunido al episcopado para pedirle que intervenga en... en el problema de estos sacerdotes, porque no quería problemas. Y no ha sido escuchado por parte de sus superiores.

P. Entonces, ¿usted dice que han recibido lo que se merecen?

M.A. No lo que se merecen, sino lo que... No sabría decirle, ¿verdad?, qué es lo que merecen, porque, si ellos hubieran sido avisados de sus superiores, por demás... El primero que murió fue uno de los que llegaba de noche y me arruinó dos comunidades de campesinos, llevándomelos hacia la izquierda.

P. ¿Quién fue?

M.A. Eh... Barrera. Y su anterior arzobispo me lo ha dicho a mí, que él se lo prohibió terminantemente. Y el que fue a celebrar misas a unas haciendas tomadas por los campesinos... De modo que yo no sabría qué decirles.

P. ¿Cuáles son los factores dentro de la Iglesia que han llevado a la situación, a la actual?

M.A. ¿Cómo es?

P. ¿Que cuáles eran los factores dentro de la Iglesia que han llevado a esta situación?

M.A. La indoctrinación de un grupo, por lo menos de unos siete sacerdotes. Estos reunieron en torno suyo a unos treinta. Yo reuní al episcopado para hacerle sabedor de lo que estaba pasando, las reuniones secretas que tenían, las formas como se citaban. Para decirles una, por ejemplo, "lunes tal, reparto de maíz a tal hora, en tal parte". Ahí se reunían los treinta sacerdotes, por lo menos dos o tres días, con prohibición de que sus obispos supieran lo que se trataba. De modo que esto no es una cosa que viene de ahora. Como por lo menos seis o siete años que se viene en esta lucha.

P. ¿Es un grupo organizado?

M.A. Organizado, organizado y todo lo demás. El primer sacerdote que murió no es - hablo de estos dos últimos, ¿no?-, fue defendido por el grupo de sacerdotes que había sido... pero inmediatamente los grupos izquierdistas declararon que pertenecía a su agrupación izquierdista. 
P. ¿Y en este último?

M.A. Eh... Por lo menos el grupo izquierdista ha tomado una revancha con la... donde murieron no sé si catorce o dieciséis guardias nacionales.

P. ¿Está diciendo que esta fue hecha por la Iglesia, por grupos sacerdotales, esta bomba?

M.A. Yo no digo, yo estaba aquí, he leído aquí, pero desde el hecho que dijeron que era para vengar la muerte del sacerdote, prácticamente estaban diciendo algo... que se entiende.

P. No entiendo, yo no entiendo.

M.A. Desde el momento que dijeron que las bombas las habían puesto en venganza de la muerte del sacerdote... pues estaban revelando algo... que como digo, yo estaba aquí en México, yo no puedo analizar bien la situación, pero ese hecho me da a mí a entender mucho, puesto que comprendo que hay muchos bemoles en la relación que, si ustedes en realidad no saben nada de El Salvador, es muy difícil saberlo comprender.

P. Monseñor, vamos al problema de esencia: ¿por qué cree usted que surgen las teologías de la liberación marxistas en América Latina, que llevan a estos sacerdotes a estas actividades?

M.A. Mire, hace por lo menos diez años, yo escribí una [carta] pastoral, en la cual Excélsior me comprometió. Yo dije en ella claramente que, desgraciadamente, en El Salvador se constataba con mucha frecuencia que eran mejor alimentados y tratados los caballos y los perros que los mismos campesinos.

P. ¿Y todavía es verdad esto?

M.A. Era cierto en aquel entonces.

P. ¿Ahora no?

M.A. Ahora, no vamos a decir que no han cambiado los señores estos, ¿verdad? Han cambiado y están cambiando un poco. Pero en aquel entonces, ningún periódico de El Salvador me publicó la pastoral.

P. ¿ ¿Pero es decir que esta situación está mejorando ahora?

M.A. Está mejorando.

P. Las cifras de las Naciones Unidas enseñan lo contrario: que, en el campo, ahora más campesinos salvadoreños están muriendo de hambre que nunca en la historia.

M.A. Ningún campesino ha muerto de hambre en El Salvador. El que afirme eso miente rotundamente. 
P. Sí... si las cifras de mortalidad por la desnutrición...

M.A. La mortalidad será por otros motivos, por salud y por todo, pero no de hambre. En El Salvador, nadie muere de hambre. Todos tienen a lo menos lo mínimo para sostenerse. Pero que eso de que afirmen que están muriendo de hambre, y si es de Estados Unidos, yo mismo lo he dicho a la delegación que llegó allí, que Estados Unidos está defendiendo derechos humanos cuándo él no los cumple allá. Por ejemplo, la división racial, el que los que lleguen de El Salvador a trabajar allá porque tienen hambre, los agarren y los saquen, y no los dejan ni ir a sacar sus centavos, que han ganado... ¡No han ido a robar a los Estados Unidos! Y han ido a ocupar trabajos que los norteamericanos no quieren, como es limpiar casas y todo eso. Y me consta que hasta han ido a tomar [a] los niños de las escuelas y llevarlos a la policía, llamar a sus papás para ponerlos en el avión, sin dejarlos sacar nada. Estados Unidos no está cumpliendo con los derechos humanos en el sentido...

P. Pero en cuanto a los derechos humanos, ha estado recientemente una comisión de la OEA...

M.A. Sí, y han estado conmigo...

P. Y han descubierto torturas terribles y más de cien personas desapa recidas, inocentes.

M.A. Mire, en eso hay que ir muy despacio, de dos casos que estaban de personas desaparecidas, y que estaban fuera del país, y sus papás girándoles dinero, y en uno de los asaltos que hubo, en uno de la... de... que asaltaron a la Guardia, cayó muerto uno de estos que estaban girándoles dinero afuera. Muchos esconden a gente para después decir que es el gobierno. Yo no estoy en favor del gobierno, ¿eh?

P. Ah, ¿no?

M.A. Y se lo digo claramente, y cuando hablo con el presidente, le digo claramente las cosas.

P. ¿Qué ha dicho usted sobre las torturas y las desapariciones, entonces?

M.A. Se lo he dicho al, pero al presidente, hablando con él.

P. ¿Pero en carta pastoral?

M.A. No, porque si me atienden, si yo tengo que hablar, ¿por qué voy a ir a la carta pastoral? Ya escribí las cartas pastorales. Cuando el presidente de la República me llamó la primera vez, estuvimos dos horas con él, y entonces, le relaté todo lo de la Guardia Nacional. Entonces, al terminar, me dijo él: "Monseñor, lo he llamado porque lo necesito; conozco su 
franqueza, su rectitud y su valentía. Tengo un problema en su diócesis con los campesinos. Mis compañeros de armas quisieran que usara las ametralladoras, los terratenientes quisieran esto, y yo no quiero eso, quiero que sea usted quien me vaya a resolver estos problemas". Y yo le he dicho al presidente: si usted está dispuesto a oír lo que nadie le ha dicho aquí, frente a su escritorio, yo estaré con usted diciéndole las cosas. Y él me ha dicho: "Eso es lo que quiero".

P. Pero siguen desapareciendo, siguen las torturas.

M.A. Pero siguen también las... siguen también los asaltos y siguen también los secuestros, y siguen también las bombas, y siguen también estos... Muchos son criminales comunes...

P. Claro, ¿pero dos males hacen un bien?

M.A. Yo no sé decirle, ¿verdad? Las autoridades tienen derecho a mantener el orden, antes...

P. ¿Por desaparecer a personas?

M.A. Antes de salir de mi diócesis, previendo lo que podía pasar, yo pedí una audiencia, al ministro de defensa, al subsecretario de la Guardia Nacional. Les hice ver todo lo que pasaba y les dije francamente: yo tengo un grupo de sacerdotes por los cuales no puedo poner la mano en el fuego, yo no me opongo a que ustedes los vigilen, porque el gobierno tiene derecho a mantener el orden público y es para mí una garantía. Lo que les pido es que no los traten mal, ni que la Guardia los ofenda ni todo esto, eh...

P. Esta división que se encuentra entre los sacerdotes, ¿se encuentra también al nivel de la jerarquía?

M.A. Desgraciadamente, sí.

P. ¿Por qué es esto?

M.A. Porque la conferencia episcopal analiza sus problemas en una forma y... no quisiera tocar este asunto, porque no quisiera faltar a la caridad, ¿verdad?, con alguno de los miembros de la conferencia episcopal, pero, desgraciadamente, algunos miembros de la conferencia episcopal están apoyando a estos sacerdotes y lo han dicho en el púlpito. Por ejemplo, la última, el penúltimo domingo, el último domingo antes de venirme, se le ha llamado al presidente de la República, desde el púlpito, mentiroso, que solo mentiras había venido a decir a México. Yo creo que eso es falta de...

P. Usted anteayer dio una entrevista... atacaron a su hermano obispo, en términos muy, muy fuertes, y en El Salvador, en primer plano, dice: "Dieciséis muertos en la Guardia Nacional... Monseñor Aparicio dice 
que los jesuitas son responsables de la situación en el país... y atacar a Monseñor Romero".

M.A. Mire, vamos con los jesuitas. Si ustedes tienen tiempo de hablar... Los primeros que me denunciaron la actitud de los jesuitas en mi diócesis fue la arquidiócesis de San Salvador. Tengo la nota y el comunicado ahí, escrito. Después, un jesuita muy importante en América Latina, en el Perú, me dijo: "Monseñor, estén atentos en El Salvador, porque los jesuitas preparan un golpe a El Salvador y al Ecuador". A los pocos meses, fue la expulsión de los obispos del Ecuador y entonces comenzó en El Salvador. Hay tres teólogos que han escrito y han... en una revista llamada $E C A$, sobre la cual la Santa Sede nos ha escrito tres veces, llamándonos la atención, una directamente a mí. Yo les comuniqué... ni siquiera me acusaron recibo. Es... tres jesuitas, por lo menos, llegaban de noche a dos comunidades mías, ¿verdad?, llamadas Cinquera y Los Llanitos. No con el nombre de jesuitas, sino con nombres fingidos, a sobornarme a los campesinos. En cuanto estos señores hacían esto con los campesinos, los otros tres teólogos se ocupaban de la parte superior. Ahora, en este momento, toda la arquidiócesis, casi los puestos claves, están en manos de los jesuitas. Por consiguiente, yo no puedo decir que los jesuitas no sean culpables de la situación que pasa el país. No puedo decir.

P. Pero la palabra del papa, aquí habló de la unidad del episcopado, la unidad...

M.A. Está bien, está bien...

P. Basados en la verdad.

M.A. Está bien. Le estoy diciendo la verdad. Yo no le estoy mintiendo.

P. ¿Cuántas veces ha saludado a Monseñor Romero aquí?

M.A. Dos veces me lo he encontrado y se me... y me huye. Yo lo he buscado, yo le escribí una carta para hablar con él, no me ha atendido en El Salvador.

P. Pero qué... piensa que él, él tiene una actitud muy distinta, y piensa que usted, ¿que él está inventando las cosas?

M.A. Yo no sé decir lo que él piensa, hasta ahí no puedo llegar.

P. Pero fueron hermanos en la conferencia episcopal desde muchos años.

M.A. Muchos años. El problema surgió hasta que él fue nombrado arzobispo. A los veinte días de haber sido nombrado arzobispo, afrentó al señor nuncio, en la conferencia episcopal.

P. Ustedes lo apoyaron... [Cambio de casete.] 
M.A. Rutilio Grande me vino a decir: "Por favor, Monseñor, háblemele usted al provincial de los jesuitas, que me quite ese elemento que tengo ahí".

P. ¿Rutilio dijo esto?

M.A. Rutilio me lo dijo a mí.

P. ¿Él no fue uno de los sacerdotes izquierdistas, entonces?

M.A. No sé hasta dónde, porque en ese sentido, no sé. Pero unos estudiantes de teología que tenía él allí, en su parroquia, esos sí.

P. Pero lo que no entiendo es cómo se hace distinción entre una denuncia sobre Rutilio por ser amigo personal y nada sobre el reciente padre Ortiz.

M.A. Porque ya el pueblo ya se da cuenta de la actitud de los sacerdotes, ya no... ya no fue sorprendido.

P. Aunque fue ametrallado en la madrugada, durmiendo.

M.A. Mire, es muy fácil decir que han sido ametrallados. Ahora se están recogiendo hasta bichos de catorce a veinte años para instruirlos en qué puesto tienen que actuar, cuando venga un enfrentamiento.

P. ¿Quiénes están haciendo esto?

M.A. A saber... Ya más no le puedo decir, no le puedo decir.

P. Bueno, ¿cómo sabe esto? Porque es una acusación muy fuerte.

M.A. Es muy común en El Salvador.

P. Ah, pero si publicamos esto, eh, es una acusación muy fuerte. Van a poner una bomba en la casa de los jesuitas, ¿no?

M.A. Mire, ayer decía uno, en el periódico, unos guatemaltecos, que más bien me interesaría que se preocuparan de Guatemala y no de El Salvador, que yo había dicho, oh, que la muerte de los jesuitas... El periodista me preguntó si era cierto, que si habían amenazado a los jesuitas de muerte, todos. Yo dije: en aquella oportunidad yo di una declaración, que cualquier atentado en esa forma contra los jesuitas era un atentado a la Iglesia. Y él sale diciendo ahí: "Y si es un jesuita, no dice nada Monseñor". Él me hizo la pregunta. Yo le contesté lo que me preguntó. Y si los periodistas no son exactos en decir lo que estamos diciendo, entonces nos enredan más. Yo traía aquí escrito, y lo tengo aquí, ¿no? Ha surgido como expresión clerical de la tendencia de grupos políticos de extrema izquierda, que buscan, según sus propias declaraciones, la total destrucción del régimen político imperante en el país y la implantación de un régimen socialista de ideología marxista-leninista. Eso lo han declarado. [Monseñor comienza a leer de un papel previamente escrito.] 
P. ¿Quiénes?

M.A. El grupo de sacerdotes.

P. ¿Cuándo?

M.A. En, en esas reuniones secretas que le digo que tienen. Porque algunos sacerdotes se infiltraron para saberlo. Por eso le digo que no podemos.

P. ¿Esto es un informe suyo?

M.A. Una información, sí.

P. ¿Esto es un informe suyo?

M.A. Sí. Y de la conferencia y de los demás obispos de la conferencia episcopal.

P. ¿Y para quién está dirigido?

M.A. Para el que lo necesite.

P. Pero, ¿no será posible divulgar esto?

M.A. Quiero... Vamos a leer: Esos grupos políticos rechazan por principio el juego de partidos, la vida democrática, por lo que son igualmente enemigos del régimen imperante como de los partidos políticos de cualquier tendencia, incluyendo al Partido Comunista. Pretenden la toma del poder por la vía de la violencia. En esos grupos políticos, militan sacerdotes de ambos cleros, religiosos, agentes laicos de pastoral. Yo tuve que prohibir todos los agentes de pastoral, porque solo estaban ocupando de eso en mi diócesis. Utilizan para la indoctrinación de ideologías políticas a los campesinos y pobladores de tugurios, las comunidades de base y los círculos bíblicos. A mí, en un pueblo, me trataron de, este, me apedrearon, pues, en el pueblo más bueno que tenía. Tácticas: debilitar al gobierno y volverlo impotente, destruir la economía del país, instrumentalizar a la Iglesia. Estrategias: presentar al gobierno ante la opinión pública internacional como conculcador de los derechos humanos y como perseguidor de la Iglesia; acusarlo continuamente de mantener reos políticos, muchos de los que presentan como tales son delincuentes comunes...

P. Pero, Monseñor, espere un momento. ¿Escapó la otra semana Reyes Cruz Menjívar, Reynaldo Cruz Menjívar, demócrata cristiano que había desaparecido?

M.A. Sí, yo le pregunté al presidente y me contesta: "¿Cree usted que un individuo esposado nueve meses, tirado en el suelo, iba a estar comiendo cucarachas y todo lo demás y se iba a escapar, e iba a salir por una reja de este tamaño?". Hay que analizarlo bien...

P. ¿Ha hablado con él? 


\section{M.A. ¿Quién?}

P. Con Cruz Menjívar.

M.A. He leído sus declaraciones.

P. ¿Y cómo estaba? ¿Él no fue demócrata cristiano?

M.A. He leído sus declaraciones. El presidente vio esto.

P. ¿No dijo que fue esposado?

M.A. Llámele a cualquier médico, digo, para que vea que, que examine la cosa, a ver qué cosa. Por eso digo que muchas cosas es necesario... ¿Por dónde iba? [Monseñor continúa leyendo.] Mantener la zozobra mediante numerosos y continuos actos terroristas en todo el país; realizar secuestros de carácter político para chantajear al gobierno, exigiéndole la liberación de los reos políticos; asesinato de guardias, policías y soldados; organizar tomas de la Cruz Roja, iglesias y embajadas.

P. ¿Quién escribió esto?

M.A. Le estoy diciendo que yo.

P. Ah, usted lo escribió...

M.A. Organizar huelgas, sabotajes de la industria, secuestros de industriales y exigencias como rescate de sumas tan grandes que los pongan al borde de la quiebra, forzando así la fuga de capitales. Se les calcula de unos ochenta a noventa millones, que tienen ya de dólares, solo de secuestros.

P. ¿Y está diciendo que sus sacerdotes están metidos en todo esto?

[Monseñor hace un gesto con la mano.]

P. No. Pero no entiendo este, la mano, ¿qué quiere decir?

M.A. ¿Qué cosa?

P. Bueno, el gesto: ¿es positivo o negativo?

M.A. Ustedes tómenlo como quieran. [Sigue leyendo.] Presentar a terroristas y activistas de los grupos clandestinos arrestados por los cuerpos de seguridad, o muertos en enfrentamientos, como catequistas o celebradores de la palabra.

P. $\quad \mathrm{Y}$, ¿no es cierto que el año pasado murieron algunos que fueron celebradores de la palabra y catequistas?

M.A. Mire, estos celebradores de la palabra están mentalizados: lo único que van a decir es: "hay división en el clero; el gobierno, aquí...". Pero nada de catequesis. Y eso, y por eso, los suprimí yo, con un decreto, en toda mi diócesis. 
P. ¿Y los diez sacerdotes que sufren suspensión?

M.A. Ya vamos a ir adelante. [Sigue leyendo.] Denunciar como persecución a la Iglesia vista de los grupos clandestinos. Hacer del arzobispado de San Salvador el símbolo de una Iglesia popular reivindicadora de los derechos humanos mediante: Primero: una adjudicación con toda bomba y con todo, del doctoramiento honoris causa; la nominación como candidato al Premio Nobel de la Paz...

P. ¿Está sugiriendo que eso fue hecho por Monseñor?

M.A. No, por los seguidores...

P. Ah. ¿Entonces, el Parlamento británico está en contacto con los seguidores?

M.A. Pues claro. Si no, no... si el Parlamento británico no tiene una información como tiene que tenerla, está faltando.

P. ¿Cuándo el viceprimer ministro lo firmó?

M.A. Cualquiera que haya sido, para mí, yo defiendo mi país, y no...

P. Sí, no, claro, pero...

M.A. Ni Inglaterra, ni Estados Unidos.

P. Esto es interesante, porque vengo de un periódico inglés. Entonces, van a interesarse que usted dice que fueron engañados...

M.A. Le voy a decir esto. Esto ya es aparte: el embajador de Inglaterra en los Estados Unidos es pariente de Makarios, si no me equivoco, sobrino; él cree que lo que pasa en El Salvador era lo mismo que Makarios estaba haciendo allá en Chipre. Y por consiguiente, parece que sus informaciones no son del todo correctas, en ese sentido...

P. ¿Él le dijo esto?

M.A. No, eso es conclusión mía, ¿verdad?, por la actuación. Yo estudio actuaciones y veo las consecuencias. Bueno... [Sigue leyendo.] La publicación y difusión de las homilías, que duran hora y media, en la cual, como digo, insulta al gobierno, insulta a los cuerpos de seguridad, insulta a la asamblea, insulta a la corte suprema de justicia, que hasta lo ha emplazado. Presentarlo, quererlo presentar, como el profeta de América Latina, o sea, un Jimmy Carter, ¿no?, haciendo en él una figura internacional. Convertir al arzobispado en el vocero de la revolución, mediante su continua denuncia del gobierno, por medio de sus homilías y a través de la radio católica YSAX, del periódico Orientación, de los boletines del arzobispado y del diario La Crónica del Pueblo, que es órgano comunista. Presentarle, semanalmente, como material de sus homilías, casos de inocentes campesinos, perseguidos por ser agentes de pastoral, para lo cual lo hacen entrevistarse 
con grupos preparados ad hoc, asesorados por activistas seglares, por sacerdotes del grupo.

P. ¿Y de los sacerdotes suyos de San Vicente, que usted suspendió?

M.A. Todavía no he terminado.

P. Ah.

M.A. [Sigue leyendo.] No permitirle dialogar con nadie que no sea de ese grupo. Mantenerle alejado de toda relación con el gobierno. Alejarlo igualmente de toda relación con la nunciatura y con las sagradas congregaciones de la Santa Sede, y relacionarlo directamente con el papa. [Termina de leer el texto.] La suspensión de los diez sacerdotes, estos diez sacerdotes, hace por lo menos ocho años, vienen enfilados en esta línea; les he llamado la atención por escrito, de palabra, en público y en privado. Uno de ellos me pidió permiso para ir a hacer estudios pastorales al Brasil; llegó a Río de Janeiro, puso tarjetas a todos, y salió para Chile, a la reunión de Cristianos para el socialismo.

P. ¿En qué año? ¿E1 72?

M.A. Sí. Desde ahí ha venido ya la cosa. Y haciéndome reuniones clandestinas y todo lo demás. Finalmente, vino un ataque a la nunciatura apostólica, fuerte. Yo leí la carta en la nunciatura apostólica. Les llamé la atención y hasta ahí hubiera llegado, pero la carta la publicaron aquí, en México; la publicaron en Guatemala y la publicaron en ese periódico comunista. Entonces, les dije: Señores, la... el nuncio apostólico es el representante personal del papa ante el gobierno y el delegado apostólico frente a la autoridad eclesiástica, y le tenemos que tener respeto. Por consiguiente, quedan suspendidos. El señor arzobispo me atacó, desde el púlpito, por eso...

P. ¿Y el Vaticano lo...?

M.A. Vamos por orden. Me atacó y cada obispo es independiente en su administración. Yo no me he metido nunca en los problemas de ellos, que no sean llevados a la conferencia episcopal. Yo informé inmediatamente al Vaticano. Entonces, ellos apelaron al Vaticano. Uno de ellos vino la misma noche a decirme que él no quería continuar así, que había sido llevado por ellos; y le levanté la suspensión inmediatamente. Los otros, al haber hecho la apelación, me dejaban a mí anulado para trabajar. Si hay una apelación al superior, el superior inmediato queda anulado. Yo fui a Roma, hablé allá, expliqué, presenté toda la documentación de cada uno de ellos, y hablando, hasta pregunté si podía levantarles la suspensión, al menos en el territorio donde ellos estaban trabajando. Me contestaron que no, porque estaban implicadas tres congregaciones, que tenían que dar sus resultados, ¿verdad? Entonces, regresé yo al país. Los ataques me fueron 
dados por un, como lo digo, no solo en el púlpito, en San Salvador, sino por los mismos periódicos, y en todo el mundo. Finalmente, ellos volvieron a escribir. Entonces, Roma me contestó: viendo que ha pasado ya un tiempo prudencial, y que ellos han escrito, deponiendo la contumacia y renovando su adhesión al romano pontífice y a la Iglesia, su excelencia, si no hay otro motivo personal o de lugar, puede levantarles la suspensión. Y entonces, se las he levantado.

P. Monseñor, de todo lo que ha hablado, parece que, según su punto de vista, será cosa buena para El Salvador si los jesuitas fueran... [Cambio de casete.] Y dijo a los periodistas que no es bueno que fueran expulsados.

M.A. Hubo demasiados teólogos y peritos, y menos obispos. [Está hablando de Medellín.] Ahora, aquí, hay más obispos que teólogos y peritos. Aquí los documentos van siendo bien... estudiados despacio por cada obispo, cada uno de los documentos.

P. ¿No se está logrando presionar de ninguna forma a los obispos aquí reunidos?

M.A. Absolutamente. Absolutamente.

P. Usted, este informe de la OEA, que está ahora disponible, usted, la conferencia episcopal, ¿lo van a tomar en cuenta, para exigir algunos cambios?

M.A. No le he entendido la pregunta.

P. Que el papa ha dicho que es deber evangélico de las iglesias, de meterse en la cuestión de los derechos humanos.

M.A. Mire, el discurso del papa va a ser un tema básico de los estudios que estamos haciendo.

P. Claro. Pero el papa es muy claro sobre derechos humanos como un deber evangélico.

M.A. Los derechos humanos todos tenemos que respetarlos. Ya le dije lo que yo he venido diciendo y hablando, y todo lo demás. Pero que muchas veces hemos caído, ¿verdad?, también nosotros, en... engañados, en cosas que eran de todos; pero que hay que trabajar por ellos.

P. Pero en este informe que han escrito estos señores, que no son norteamericanos, sino de todos los países, que compusieron esta misión a El Salvador, el año pasado, han descubierto en la Guardia Nacional bartolinas, exactamente como las ha descrito el señor Cruz Menjívar, han descubierto las camas donde él dijo que fue esposado, han descubierto lugares de interrogación con electrodos: toda esta cuestión, lo han visto, y están diciendo que hay un prima facie caso de torturas... 
M.A. Mire, esto yo se lo digo, ellos llegaron a hablar conmigo, llegaron cabalmente con el jefe del estado mayor, delante de ellos, a mí no me han dicho nada. Entonces...

P. Monseñor, ¿usted se encontró con la delegación de mujeres que fueron por aquí... la semana pasada?

M.A. No, no la vi, me dijeron que habían estado, pero no las vi.

P. ¿Y su opinión sobre esa visita?

M.A. Pues que han sido enviadas ex profesamente para eso.

P. ¿Por parte de quién?

M.A. De estos grupos izquierdistas. No le digo que tienen dinero para todo...

P. ¿Usted cree entonces que ellas no tienen hijos desaparecidos y todo lo que están reclamando?

M.A. Algunas, puede ser. Como le digo, mire, uno del gobierno no tiene que, ¿verdad?, pero tampoco puede ser uno tan necio de querer, cómo le dijera, aplicarle todo a él. Yo no lo defiendo, yo se los digo claramente. Cuando hay un caso, yo le llevo al ministro de defensa un sacerdote que me lo habían golpeado, pero él no me lo dijo a mí: se lo fue a decir al arzobispo. A los tres meses, que me lo vino a decir a mí, le dije: venite conmigo. Señor ministro, oiga aquí el relato de este sacerdote. Y lo oyó. Y el ministro le dijo: "Padre, tenga la bondad de dispensarnos, porque aquí en el ministerio somos los últimos en saber estas cosas. Usted me dice que el cabo de la Guardia no tuvo culpa, y ha sido el más culpable, padre", me dijo, "porque a la orden de él iban esos guardias; y yo investigaré el caso".

P. Monseñor, ¿cree usted que estas mujeres, yo estuve en la conferencia de prensa, donde estuvieron estas señoras, y estas señoras pidieron por la vida de sus hijos, pero nunca pidieron por la vida de aquellos que habían sido raptados para ver si rescataban a sus hijos, por la vida de aquellos que habían sido raptados y estaban amenazados de muerte. ¿Por qué cree usted que es esto?

M.A. Mire, como le digo, yo no estoy muy al tanto, y de lo que no estoy muy al tanto, no me gusta hablar, porque puedo equivocarme. Yo hablo de lo que en realidad estoy...

P. ¿Eso no podría confirmar su suposición de que esas personas han sido mandadas ex profeso aquí?

M.A. Eh... Esas personas no tenían, ciertamente, los medios para venir, ¿verdad? $\mathrm{Y}$ han sido buscadas y enviadas para esto. Yo casi lo creo así, por cuanto estudio el mecanismo que llevan ellos allá. 
P. Pero usted ha dicho que podría ser que algunas de ellas sí habrían perdido a sus queridos hijos o hijas...

M.A. Yo no le digo que no, y cabalmente, yo hablé fuerte: si los señores obispos son sinceros, cuando nos hemos reunido todo el episcopado con el gobierno, yo he sido el que he hablado más fuerte.

P. Pero si hay uno que ha perdido a su hijo, ¿no un alma es como uno de los... se deja a los 99 para buscarlo?

M.A. No le vamos a decir que no. Si yo no le estoy negando absolutamente nada. Le digo que la situación es muy confusa. Y que difícilmente yo voy a creer una cosa porque me la dice este o porque me la dice aquel: yo voy al fondo, a ver si es cierto. Pero solo porque me lo vengan a decir, no. A los campesinos les he dicho claramente, porque llegan: Miren, yo uso una palabra, ustedes son muy taimados, ustedes me vienen a contar las cosas como a ustedes les parece. Pero yo quiero saber la realidad, como un delincuente le habla a su abogado. Y entonces, yo veré cómo los defiendo, cómo actúo por ustedes. Pero si no me dicen las cosas claras, llego yo a Casa Presidencial, o llego a otra cosa, y me salen con lo contrario, ¿eh? Y entonces, ¿dónde vamos a parar? Díganme si han cometido el delito, díganmelo: voy a ver cómo hago, pero necesito saber las cosas claras...

P. Monseñor, ¿cómo ve usted la posibilidad de reunir a la Iglesia salvadoreña?

M.A. Mire, el presidente de la República, me consta, ha hecho todo lo posible por entrevistarse con el señor arzobispo, inclusive uno de los embajadores de El Salvador los invitó a cenar a los dos juntos, para poner su mediación, y el arzobispo contestó que él no iba, porque no quería tener ninguna relación con el presidente. Ahora... Monseñor, una vez sí le mandó decir que podían tener un encuentro, pero fuera del país. Entonces, el presidente dice: "yo no puedo salir del país para un encuentro con el arzobispo".

P. Pero yo estoy hablando más bien de dentro de la Iglesia...

M.A. Dentro de la Iglesia, lo primero sería eso, ¿no?, que ellos se pusieran de acuerdo; porque mientras no estén así...

P. ¿Quiénes?

M.A. El gobierno con el arzobispado.

P. ¿Antes de la unidad de la Iglesia?

M.A. Sí, porque él pone como pretexto eso: Nosotros hemos trabajado y hemos hecho reuniones, todo para ver, pero... ¿qué podemos hacer? Díganme ustedes. Cuando hemos tenido reuniones y él llega, él entra y sale y entra, 
y nunca está toda la reunión. Y muchas veces, cuando ya se han hecho las votaciones o se llega al punto difícil, él no está presente.

P. ¿Está diciendo entonces, Monseñor, que realmente depende la unidad de la Iglesia salvadoreña del gobierno?

M.A. No, del arzobispo. Si el arzobispo entra en contacto con nosotros y entra en contacto con el gobierno, entonces las cosas...

P. No entiendo muy bien cómo el gobierno entra en esta cosa tanto; porque, me parece a mí, la disensión entre el arzobispo, los obispos, el clero y los fieles...

M.A. Es que cuando pasó la muerte del padre Grande, él dio una declaración, diciendo que mientras no se supiera quién había matado al padre Grande, la Iglesia no tendría relaciones con el gobierno. Él no dijo el arzobispado: él dijo la Iglesia. Entonces, la conferencia episcopal le dijo: "No, señor, usted debía haberlo consultado antes, para dar esa declaración".

P. Pero, zustedes no piensan que, dada la naturaleza de las cosas, ustedes deben solidarizarse?

M.A. Nos solidarizamos al principio y yo escribí un documento, y yo lo firmé, porque los demás obispos no lo iban a firmar, defendiéndolo a él; pero él no ha actuado como debía, él no atiende a la conferencia episcopal, sino al grupo de sacerdotes que él tiene de... Mire, a mí me apena tener que decir esto, yo no quería, yo andaba huyendo de los periodistas, porque no quería, tengo mucho que decir y soy muy franco para hablar...

P. Una última pregunta. Durante este tiempo, ha dicho varias veces, en esta entrevista, que no está con el gobierno.

M.A. No.

P. Mire...

M.A. No he dicho que no estoy con el gobierno: que no acepto todas las actitudes del gobierno. Pero que se las digo.

P. ¿Qué piensa del gobierno, usted?

M.A. Yo pienso del gobierno lo que en una oportunidad el jesuita Poblete nos dijo, en Costa Rica: estos hombres desde los diecisiete años están formados en una mentalidad castrense, en una disciplina regia, y todo lo que ellos piensan lo piensan a través de una mentalidad castrense, como nosotros pensamos todo en una mentalidad eclesiástica; y ellos creen que la Iglesia es lo mismo que ellos, y que nosotros podemos mandar como mandan ellos. Y firme, mi coronel, y se acabó, ¿verdad? Y ahí está. Yo le dije: ¿por qué no permiten ustedes que un sacerdote cualquiera, pero 
preparado, vaya a la escuela militar y les dé unas pláticas a los cadetes, a los maestros y todo, porque no saben nada de la parte religiosa?, y me lo han aceptado. Dicen que sí, que están dispuestos a eso: porque en realidad, ellos necesitan saber.

P. ¿Eso es lo más fuerte que tiene que decir sobre el gobierno?

M.A. ¿Quién?

P. Usted.

M.A. Bueno...

P. Usted ha atacado a Monseñor Romero muchas veces en esta entrevista; pero nada sobre el gobierno.

M.A. No lo he, no lo he atacado: he dicho lo que es. Porque una cosa es atacar y otra cosa es decir la verdad. Y eso es lo que no me gusta de los periodistas, ¿verdad?, que muchas veces uno... no agarran el hilo. Yo he dicho la actitud de él; no lo he atacado, ni lo ataco. Yo reconozco en Monseñor Romero a un hombre preparado, inteligente, capaz de todo, ¿verdad?, porque yo mismo lo llamé a la conferencia episcopal, cuando yo era presidente, la vez pasada. Él era párroco en San Miguel. Si viendo sus aptitudes intelectuales, yo mismo lo llamé a la conferencia episcopal. De modo que yo aprecio en él aptitudes muy especiales; pero esta actitud actual, esa no se la apruebo.

P. Una pregunta final de mi parte. ¿Cree usted, Monseñor, que los problemas de El Salvador se pueden resolver sin cambios fundamentales...?

[Fin del casete.] 